\title{
A Demonstration of Man of Electromotive Changes Accompanying the Heart's Beat
}

\author{
Augustus D. Waller, M.D.
}

If a pair of electrodes (zinc covered by chamois leather and moistened with brine) are strapped to the front and back of the chest, and connected with a Lippmann's capillary electrometer, the mercury in the latter will be seen to move slightly but sharply at each beat of the heart. ${ }^{1}$ If the movements of the column of mercury are photographed on a travelling plate simultaneously with those of an ordinary cardiographic lever a record is obtained as under (Fig. 1) in which the upper line h.h. indicates the heart's movements and the lower line e.e. the level of the mercury in the capillary. Each beat of the heart is seen to be accompanied by an electrical variation.

The first and chief point to determine is whether or no the electrical variation is physiological, and not due to a mechanical alteration of contact between the electrodes and the chest wall caused by the heart's impulse. To ascertain this point accurate time-measurements are necessary; a physiological variation should precede the movement of the heart, while this could not be the case if the variation were due to altered contact. Figure 2 is an instance of such time-measurements taken at as high a speed of the travelling surface as may be used without rendering the initial points of the curves too indeterminate. It shows that the electrical phenomenon begins a little before the cardiographic lever begins to rise. The difference of time is however very small, only about .025", and this amount must further be diminished by $.01^{\prime \prime}$ which represents the "lost time" of the cardiograph. The actual difference is thus no greater than .015", and the record is therefore, although favourable to the physiological interpretation, not conclusively satisfactory.
We know, from the experiment of the secondary contraction made by Helmholtz ${ }^{1}$ on voluntary muscle, by Kölliker and Müller ${ }^{2}$ and by Donders ${ }^{3}$ on the heart, that the negative variation of muscle begins before its visible movement, and the current of action of the heart begins before the commencement of the heart's contraction. For muscle the time-difference given is $\frac{1}{200} "$, for the heart (rabbit) $\frac{1}{70}{ }^{\prime \prime} ;$ for the frog's heart the rheotome observations of Marchand ${ }^{4}$ are to the effect that the variation begins $.01^{\prime \prime}$ to $.04^{\prime \prime}$ after excitation, while the contraction does not begin until .11" to .33". The capillary electrometer may with advantage be employed to measure this time-difference, the electrical and the mechanical events being simultaneously recorded. This I carried out on voluntary and upon cardiac muscle with the same instrument as that which I employed for the human heart, and thus ascertained that its indications are trustworthy in this capacity.

In all these cases the antecedence of the electrical variation is clear and measurable. In the case of the excised kitten's heart the time-difference is about $.05^{\prime \prime}$ with a length of contraction of about $2^{\prime \prime}$, i.e. the interval between the electrical and the mechanical event is increased in the sluggishly acting organ. In the case of the human heart the time-difference appears to be about .015" with a length of systole of $.35^{\prime \prime}-$ a value which corresponds with that obtained by Donders for the rabbit's heart in situ by the method of the secondary contraction, viz. $\frac{1}{70}{ }^{\prime \prime}$ (the length of systole being presumably about $\frac{1}{3}^{\prime \prime}$ ).

That a true electrical variation of the human heart is demonstrable, may further be proved beyond doubt by leading off from the body otherwise

\footnotetext{
${ }^{1}$ The capillary column of mercury is vertical; the electrode connected with the mercury will be spoken of as the "Hg electrode," that connected with the sulphuric acid as the " $\mathrm{H}_{2} \mathrm{SO}_{4}$ electrode." When the Hg electrode becomes negative to the $\mathrm{H}_{2} \mathrm{SO}_{4}$ electrode the mercury moves away from the point of the capillary-i.e. northwards in the field of the microscope with eye-piece, or when projected without eye-piece. When the $\mathrm{H}_{2} \mathrm{SO}_{4}$ electrode becomes negative to the Hg electrode the movement of the mercury is southwards. The letters $S$ and $N$ will be used to characterise such movements. When these movements are photographed, the mercury interrupting the light of a vertical slit gives the white portion of the developed sensitive plate, the remaining portion being black with the exception of the white lines caused by the chronographic or other levers which throw their shadows across the upper part of the slit. The tracings read from left to right
} 


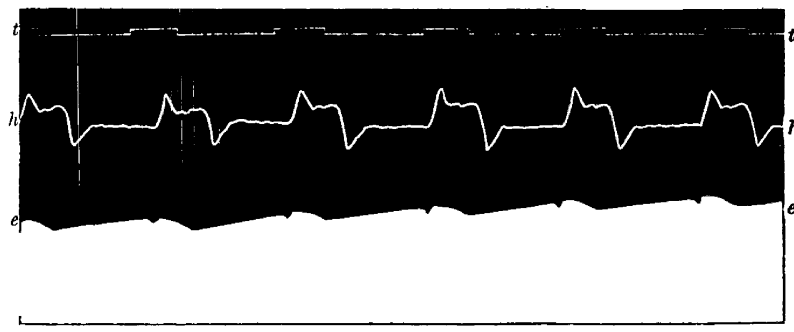

Figure 1. Man. Heart led off to electrometer from front and back of chest (front to $\mathrm{Hg}$; back to $\mathrm{H}_{2} \mathrm{SO}_{4}$ ). e.e. electrometer. h.h. cardiograph. t.t time in seconds.

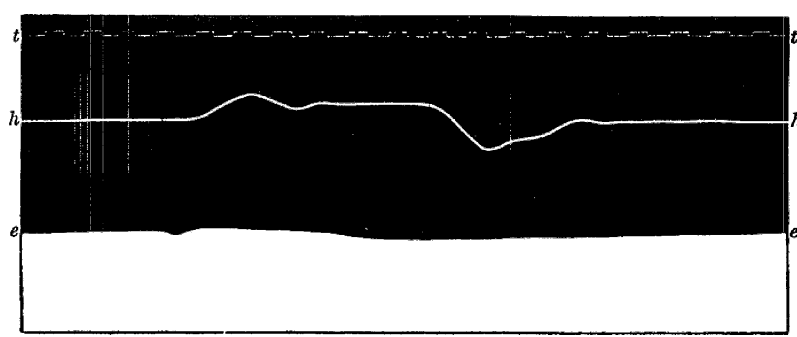

Figure 2. Man. Heart led off to electrometer from front and back of chest (front to $\mathrm{Hg}$; back to $\mathrm{H}_{2} \mathrm{SO}_{4}$ ). e.e. electrometer. h.h. cardiograph. t.t. time in $\frac{1}{20}$ th sec.

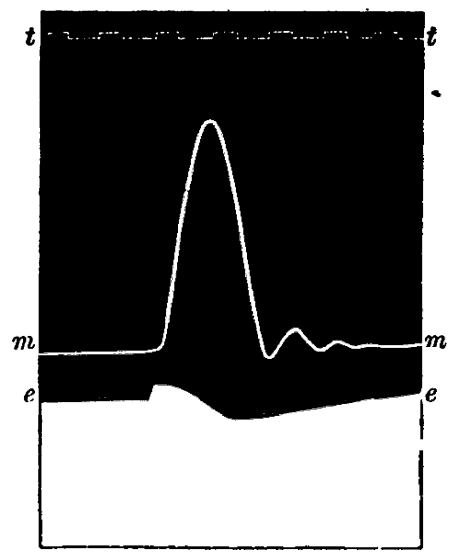

Figure 3. Frog. Gastrocnemius led off to electrometer from the middle of the muscle and from the tendon. Contraction excited by a single break induction shock applied to the sciatic nerve. e.e. electrometer. m.m. muscle. t.t. time in $\frac{1}{20}$ th $\mathrm{sec}$. (muscle to $\mathrm{H}_{2} \mathrm{SO}_{4}$; tendon to $\mathrm{Hg}$ ). The diphasic variation (Ist phase middle negative to end; 2 nd phase end negative to middle) begins about .01" before the commencement of muscular contraction.

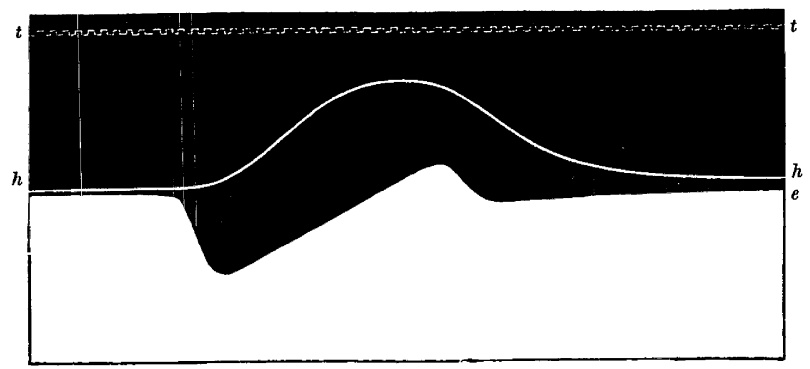

Figure 4. Frog's heart. Spontaneous contraction. e.e. electrometer. h.h. heart's contraction. t.t. time in $\frac{1}{20}$ th sec. (apex to $\mathrm{H}_{2} \mathrm{SO}_{4}$, base to $\mathrm{Hg}$ ). The variation is diphasic-S. N. The first phase begins $\frac{1}{10}$ " before the commencement of contraction.

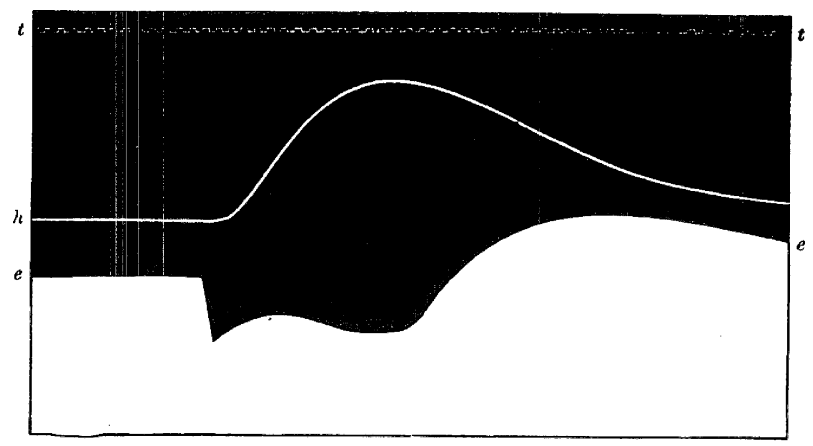

Figure 5. Kitten's heart, excised. (apex to $\mathrm{Hg}$. base to $\mathrm{H}_{2} \mathrm{SO}_{4}$ ). electrometer. h.h. cardiograph. t.t. time in $\frac{1}{20}$ th sec.

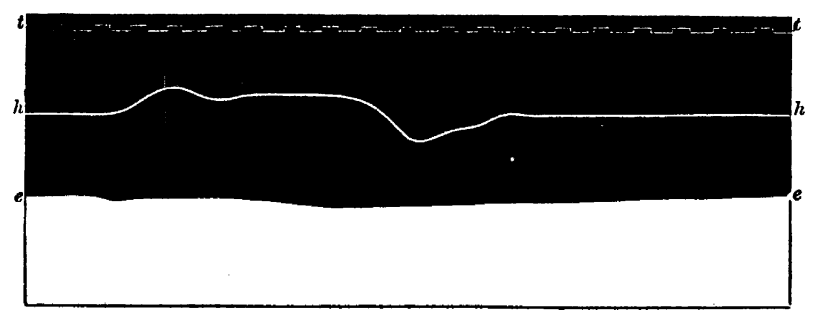

Figure 6. Man. Led off to electrometer by right hand and right foot. (hand to $\mathrm{Hg}$. foot to $\mathrm{H}_{2} \mathrm{SO}_{4}$ ). e.e. electrometer. h.h. cardiograph. t.t. time in $\frac{1}{20}$ th sec.

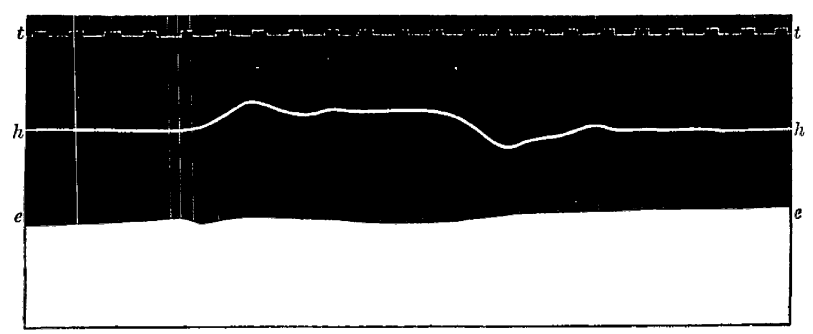

Figure 7. Man. Led off to electrometer by mouth and left foot. (mouth to $\mathrm{Hg}$. foot to $\mathrm{H}_{2} \mathrm{SO}_{4}$ ). e.e. electrometer. h.h. cardiograph. t.t. time in $\frac{1}{20}$ th sec. 


\begin{tabular}{|c|c|c|c|c|}
\hline & & & & $\begin{array}{l}\text { Electrode } \\
\text { Reversed }\end{array}$ \\
\hline Precordium to $\mathrm{H}_{2} \mathrm{SO}_{4}$ & Back to & $\mathrm{Hg}$ & SS variation & NN \\
\hline Precordium to $\mathrm{H}_{2} \mathrm{SO}_{4}$ & Left hand to & $\mathrm{Hg}$ & SS variation & NN \\
\hline Precordium to $\mathrm{H}_{2} \mathrm{SO}_{4}$ & Right hand to & $\mathrm{Hg}$ & SS variation & NN \\
\hline Precordium to $\mathrm{H}_{2} \mathrm{SO}_{4}$ & Left foot to & $\mathrm{Hg}$ & SS variation & NN \\
\hline Precordium to $\mathrm{H}_{2} \mathrm{SO}_{4}$ & Right foot to & $\mathrm{Hg}$ & SS variation & NN \\
\hline Left hand to $\mathrm{H}_{2} \mathrm{SO}_{4}$ & Right hand to & $\mathrm{Hg}$ & SS* variation & NN \\
\hline Left hand to $\mathrm{H}_{2} \mathrm{SO}_{4}$ & Left foot to & $\mathrm{Hg}$ & ? variation & $?$ \\
\hline Left hand to $\mathrm{H}_{2} \mathrm{SO}_{4}$ & Right foot to & $\mathrm{Hg}$ & ? variation & ? \\
\hline Right hand to $\mathrm{H}_{2} \mathrm{SO}_{4}$ & Right foot to & $\mathrm{Hg}$ & NN* variation & SS \\
\hline Right hand to $\mathrm{H}_{2} \mathrm{SO}_{4}$ & Left foot to & $\mathrm{Hg}$ & NN variation & SS \\
\hline Right foot to $\mathrm{H}_{2} \mathrm{SO}_{4}$ & Left foot to & $\mathrm{Hg}$ & O variation & $\mathrm{O}$ \\
\hline Mouth to $\mathrm{H}_{2} \mathrm{SO}_{4}$ & Precordium to & $\mathrm{Hg}$ & NN variation & SS \\
\hline Mouth to $\mathrm{H}_{2} \mathrm{SO}_{4}$ & Right hand to & $\mathrm{Hg}$ & O variation & SS \\
\hline Mouth to $\mathrm{H}_{2} \mathrm{SO}_{4}$ & Left hand to & $\mathrm{Hg}$ & $\mathrm{NN} *$ variation & SS \\
\hline Mouth to $\mathrm{H}_{2} \mathrm{SO}_{4}$ & Right foot to & $\mathrm{Hg}$ & NN variation & SS \\
\hline Mouth to $\mathrm{H}_{2} \mathrm{SO}_{4}$ & Left foot to & $\mathrm{Hg}$ & NN variation & SS \\
\hline
\end{tabular}

than from the chest wall. If the two hands or one hand and one foot be plunged into two dishes of salt solution connected with the two sides of the electrometer, the column of mercury will be seen to move at each beat of the heart, though less than when electrodes are strapped to the chest. The hand and foot act in this case as leading off electrodes from the heart, and by taking simultaneous records of these movements of the mercury and of the movements of the heart it is seen that the former correspond with the latter, slightly preceding them and not succeeding them, as would be the case if they depended upon pulsation in the hand or foot. This is unquestionable proof that the variation is physiological, for there is here of course no possibility of altered contact at the chest wall, and any mechanical alteration by arterial pulsation could only produce an effect $.15^{\prime \prime}$ to $.20^{\prime \prime}$ after the cardiac impulse. A similar result is obtained if an electrode be placed in the mouth while one of the extremities serves as the other leading off electrode. The electrical variation precedes the heart's beat as in the other cases mentioned.

In conclusion it will be well to allude to the difficulties which arise in the interpretation of the character of the electrical variation of the human heart.

By mere inspection of the electrometer it is often most difficult to determine the direction of very rapid movements of the mercury, and photography must be employed. But even then, owing to the small amplitude of movement, it is still difficult to say whether the variation consists of two movements, and whether each movement indicates a sin- gle or a double variation in the same direction. Differences in the position of the electrodes also give rise to differences of the apparent variation. Thus with the following position of the electrodes $(\mathrm{Hg}$ electrode over the apex beat, $\mathrm{H}_{2} \mathrm{So}_{4}$ electrode on the right side of the back) the variation as watched through the microscope appears usually $\mathrm{nN}$, and changes to $\mathrm{SN}$ if the $\mathrm{Hg}$ electrode be shifted to the sternum. If the $\mathrm{Hg}$ electrode is on the back and the $\mathrm{H}_{2} \mathrm{SO}_{4}$ electrode over the apex beat, the variation appears to be sS and to become $\mathrm{nS}$ when the $\mathrm{H}_{2} \mathrm{SO}_{4}$ electrode is shifted away from the apex beat. The variations accompanying the heart's beat observed as carefully as possible (without the aid of photography) on a healthy person with different positions of the leading off electrodes were as follows. It is to be remarked that the direction of variation as observed in this series is not such as to indicate negativity of the cardiac electrode but the reverse.

It is on account of these sources of doubt that I have not thought it advisable at this stage to attempt a definite interpretation of the character of the variation, which although as shown, especially by the experiments illustrated in Figs. 6 and 7, is certainly physiological, may nevertheless be physically complicated by the conditions of demonstration on the human body.

\section{REFERENCES}

1. Monatsberichte Berlin Acad. 1854. p. 829.

2. Verhandl. phys. und. Gel. Würtzburg, 1856, VI. p. 528.

3. Onderzoekingen, Utrecht, 1872, p. 261.

4. Pflüger's Archiv xv. 1877, 511. 